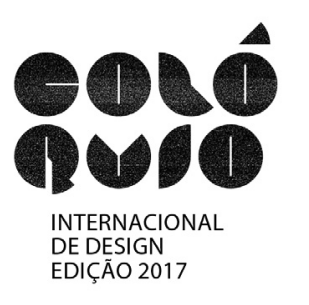

\title{
Design, Identidade e Metodologias Participativas
}

\author{
Sâmela Suélen Martins Viana Pessôa; \\ Álisson Valentim de Freitas; \\ Luiz Henrique de Sena Nola.
}

resumo:

O principal desafio do designer na contemporaneidade é desenvolver e suportar o desenvolvimento de soluções orientadas às questões de alta complexidade. O caráter mediador do design estabelece qualidade aos processos, sendo um fator central para a humanização de tecnologias e troca cultural. Desta forma, é preciso refletir sobre o desenvolvimento de novas ferramentas e métodos de trabalho que propiciem o diálogo e a inclusão de camadas sociais no processo de concepção de soluções que visem o atendimento das necessidades deste público. Para isso, o presente artigo irá apresentar a cidade como um contexto vivo que integra diferentes pessoas, hábitos e cultura. Nesse sentido, o designer tem um importante papel de contribuir para a valorização da identidade territorial, por meio de processos participativos quem podem estimular o senso de pertencimento. Assim, neste estudo, objetiva-se refletir sobre os procedimentos de coleta de informações que norteiam a ação de design com o intuito de discutir novas diretrizes para coleta da percepção e condução de ações que favoreçam a inserção dos usuários. Propõem-se assim, como procedimentos desse processo um fluxo dialético apoiado no conceito "flaneur", apresentado por Charles Baudelaire, que compreende um olhar perceptivo sobre o contexto e que neste estudo consiste na capacidade de olhar, ouvir e dar voz. Como objeto de estudo para essa reflexão, será apresentado um relato acerca do projeto: "praça de bolso do ciclista", realizado na cidade de Curitiba / PR, em 2014. A ação utilizou de instrumentos participativos e que se tornam referência para o processo de design, pelo seu potencial de transmitir o senso de pertencimento e empoderamento à comunidade. Acredita-se assim, que formas criativas e participativas de se ocupar o espaço público podem contribuir para um novo pensamento diante do desafio da ressignificação, identidade e do senso de patrimônio coletivo na cidade. Nessa nova perspectiva, o designer se torna mais que um projetista, se apresenta como um agente de conexão e mediação entre a identificação de um problema e a busca por uma solução que considere amplas percepções de diferentes agentes inseridos no contexto da ação.

palavras-chave:

Identidade; território; design participativo; dar voz. 


\section{Introdução}

$\mathrm{O}$ artigo inicia-se com reflexões sobre design, cidade e cultura que visam apresentar a relação das pessoas com o espaço em que estão inseridas e todas as manifestações presentes. Assim, identificar os fenômenos presentes ao redor de cada contexto social se faz necessário para a proposição de soluções que sejam relevantes. Reflete-se sobre como o âmbito social do design pôde contribuir para solucionar problemas referentes à cultura do indivíduo. Em sequência, será apresentado conteúdo a respeito do designer na perspectiva do olhar interpretativo, no qual baseia-se na definição apresentada por Charles Baudelaire do conceito "flaneur" que remete ao olhar perceptivo, de quem anda pela cidade a fim de experimentá-la. Essa abordagem introduz a ideia da necessidade de ampliação da percepção do designer com relação aos contextos nos quais se insere. No mundo atual, no qual os processos se tornam cada vez mais tecnológicos e virtuais, provoca-se a reflexão sobre a necessidade de adotar novos comportamentos e mecanismos que permitam ao designer desacelerar para perceber e codificar com maior assertividade os contextos nos quais se insere.

O presente artigo objetiva refletir sobre os procedimentos de coleta de informações que norteiam a ação de design. Tal ação auxilia o designer na identificação das necessidades dos usuários. Assim, se faz necessário conhecer as preferências e o modo como cada pessoa significa e atribui sentidos. Por isso, discutem-se novas diretrizes para perceber e conduzir as ações de design a fim de favorecer a inserção dos usuários no processo de concepção de soluções. Propõem-se assim como atos desse processo: olhar, ouvir e dar voz.

Por fim será apresentado um relato acerca do projeto praça de bolso do ciclista que demonstra uma ação de caráter participativo, na qual o espaço se configura como um patrimônio coletivo. Por meio de uma ação colaborativa que envolveu agentes da comunidade foi possível interpretar a realidade social e inserir diferentes usuários no processo de concepção e execução de uma praça, garantindo assim a apropriação e o senso coletivo de pertencimento com o espaço. Essa ação apresenta um cenário de possibilidades de atuação para o designer que passa a repensar seu papel social. Assim, discute-se o papel do designer na valorização da identidade territorial a fim de estimular o senso de pertencimento.

\section{Design, Cidade e Cultura}

A cidade é um organismo vivo, onde transitam pessoas dos mais diferentes hábitos e costumes. Essa miscelânea de culturas que constitui a urbe é o cenário de relações que fogem do simples lugar de passagem e ganha contornos mais resistentes ao analisarmos os conflitos presentes neste espaço. Em um contexto tão diverso, presenciamos questões desiguais. A análise das desigualdades do espaço urbano, que confronta classes colocando lado a lado pessoas de conjunturas opostas, nos leva a pensar sobre meios que amenizem as disparidades.

Projeto se refere à dimensão antropológica, interpretação da democracia, no sentido de possibilitar a participação. Isso significa criação do espaço para um projeto próprio, para um Design próprio. Os designers têm a tarefa de reconciliar essas duas polaridades, a polaridade entre o material e o simbólico, entre estrutura externa e interna. O design se encontra na intersecção entre a cultura da vida cotidiana, da tecnologia e da economia. Nos cenários de uma cidade há espaços que foram esquecidos, lugares reais, mas que estão fora dos lugares aceitos. São 'desvios' devidos aqueles comportamentos que estão fora do que a sociedade aceita e impõe às condutas.

A cidade hoje é feita de cenários diversos e complexos que se comunicam em um processo iterativo de frequente mutação, calcado na participação de agentes reais que exercem influência na ocupação do espaço. Esses agentes compõem a identidade do território que estão inseridos, ainda que este espaço seja esquecido ou esteja em uma linha de 'desvio' no que tange as aceitações 
comportamentais da sociedade. Para esta situação o conceito da heteropia, elaborado por Foucault (1984) mostra que é nestes espaços que estão contidos os conflitos e tensões que se exercem pelas relações de poder de uma sociedade determinada. Dessa maneira, é preciso transformar o conhecimento solitário em solidário, promover a espacialização das informações, dispor percepções e ideias em uma escala acessível. Identidade e globalização ocupam uma posição central no discurso atual do Design.

Ferrara (2007) diz: "a cidade, enquanto texto não-verbal é uma fonte informacional rica em estímulos criados por uma forma industrial de vida e de percepção". A leitura desses estímulos criados pela indústria evidencia a necessidade de aproximação com quem constrói a cidade todos os dias. Identificar os fenômenos presente ao redor de cada contexto social se faz necessário para propormos soluções que agreguem a sua realidade.

Cada pessoa constrói ao longo de sua vida uma rede de significados, que por meio dela desenvolve pensamentos, valores, condutas, análises que darão sentido a sua existência (Geertz,1989). Os estilos de vida são manifestações resultantes da capacidade de estruturar, práticas e esquemas de percepção e apreciação, e ser estruturado pelas condições e posições sociais, vinculados à cultura de cada sujeito e grupos sociais. Eles se expressam por meio de hábitos estéticos, estruturas de preferências e gostos distintos, influenciados por instituições e estruturas materiais que administram, transmitem e renovam o capital cultural (BOURDIEU, 1983).

Nesse sentido, o design se apresenta como ferramenta de inclusão e identidade, capaz de solucionar problemas de alta complexidade e contribuir para a diversidade, como a grande colcha de retalhos que é a cidade. O caráter mediador do design favorece e incentiva a combinação de conhecimentos de múltiplos campos. Este aspecto transversal colabora e caracteriza os resultados como uma inovação sócio-cultural, fundamentada no sucesso e satisfação da sociedade (BONSIEPE, 1998).

Nessa perspectiva, o design visa oferecer benefícios para a comunidade humana como um todo. A ação do designer se conecta com a necessidade de entender os vínculos sociais e perceber sua própria identidade para determinar objetivos em circunstâncias complexas. Esse entendimento está ligado ao dever de lidar com a diversidade pluralística da sociedade e sua empatia com os grupos heterogêneos (KRUCKEN, 2008).

Assim, todos os fenômenos de estímulos e influências, estão diretamente relacionados ao comportamento de consumo e à cultura. Sob este olhar, o designer se coloca como agente promotor de mudanças daquilo que tem sido feito até o momento. É notória as interferências de uma camada sobre a outra, porém a dualidade 'dominador/dominado' deve ser deixada de lado, sendo que para cada meio há uma necessidade e um desejo específico, não sendo esse de menor valor para determinado grupo, mas sim de importância relevante para todos.

Suprir a carência da valorização de identidade territorial é o papel do designer. Cabe a ele estimular esse senso de pertencimento. "Quanto mais a tal da globalização avança trazendo consigo a desterritorialização, mais [...] a gente sente necessidade de pertencer a algum lugar, àquele canto do mundo específico que nos define" (BORGES, 2003).

Neste quesito vemos como o âmbito social do design pode contribuir para solucionar problemas referentes à cultura do indivíduo. Segundo Ono (2004), as culturas são o que moldam as identidades, as quais são múltiplas e que o indivíduo pode assumir a que lhe parecer mais adequada, baseando-se na necessidade de se familiarizar ou de se diferenciar de algo ou alguém. $\mathrm{O}$ design é tanto uma prática social como uma reflexão sobre ela (SCHNEIDER, 2010). Ele é ideológico, pois interpreta a realidade social, podendo modificar relações e propor soluções.

A capacidade de revelar interesses econômicos, políticos e juízos de valor, faz nos entender como o designer, até então visto distante da possibilidade de sanar tais problemas, pode reverter a situação e ser o curinga capaz de conduzir a ruptura com o sistema atual. 


\section{0 designer e o olhar interpretativo}

O designer poderá ser mais que um projetista, ele se apresenta como um elemento de conexão e mediador entre a identificação de um problema e a busca por uma solução. Para isso, a atuação do designer transcende a configuração dos elementos materiais, determinados pelos aspectos físicos, alcançando assim a imaterialidade (STRAUB; CASTILHO, 2010). Essa é a forma com que o designer se comunica, contando histórias a partir de elementos. Nesse sentido, os objetos de criação do designer têm a capacidade de estimular os aspectos sensoriais dos usuários e mais do que isso, tem o potencial de transformar modos de vida.

Em contrapartida, a formação acadêmica tem o papel de oferecer subsídio ético, científico e ferramental para que o designer em formação possa atuar. Sobre o processo de formação e desenvolvimento do conhecimento, Kant (1980) considera que nenhum conhecimento precede a experiência, todos começam por ela. Também traz em sua abordagem o seguinte relato:

(...) nossos conhecimentos começam com a experiência, porque, com efeito, como haveria de exercitar-se a faculdade de se conhecer, se não fosse pelos objetos que, excitando os nossos sentidos, de uma parte, produzem por si mesmos representações, e de outra parte, impulsionam a nossa inteligência a compará-los entre si, a reuni-los ou separá-los, e deste modo à elaboração da matéria informe das impressões sensíveis para esse conhecimento das coisas que se denomina experiência? (KANT, p. 09, 1980).

Desse modo, a experiência é fundamental no processo de aprendizagem e está diretamente relacionada as possibilidades de vivenciar realidades que permitam a proximidade com os usuários. Krucken (2008) vai relatar sobre a importância do designer estar familiarizado com o uso de tecnologias e ferramentas de uso interativo. Além disso, necessita relacionar a informação e o conhecimento. Assim, ressalta a importância da empatia e de relacionar-se bem com as pessoas do processo, que lhe permitirá desempenhar satisfatoriamente a gestão do processo de design com vistas a resolução de um problema. Surge assim autonomia no processo, por meio da ampliação da consciência acerca dos direitos e responsabilidades que permitem a consolidação do aprendizado. Portanto, o lugar do designer é no meio das manifestações e dos fenômenos sociais.

Nesse sentido, Charles Baudelair, no século XIX, apresenta um conceito experimental orientado a prática da observação dos fenômenos sociais conhecido como "flanar". O verbo vem do flâneur que significa a observação da vida urbana. Diz respeito ao ato de divagar pela cidade a fim de experimentá-la conforme apresentado abaixo:

Flanar é ser vagabundo e refletir, é ser basbaque e comentar, ter o vírus da observação ligado ao da vadiagem. Flanar é ir por aí, de manhã, de dia, à noite, meter-se nas rodas da populaça, admirar o menino da gaitinha ali à esquina, seguir com os garotos o lutador do Cassino vestido de turco, gozar nas praças os ajuntamentos defronte das lanternas mágicas, conversar com os cantores de modinha das alfurjas da Saúde, depois de ter ouvido dilettanti de casaca aplaudirem o maior tenor do Lírico numa ópera velha e má; é ver os bonecos pintados a giz nos muros das casas, após ter acompanhado um pintor afamado até a sua grande tela paga pelo Estado; é estar sem fazer nada e achar absolutamente necessário ir até um sítio lôbrego, para deixar de lá ir, levado pela primeira impressão, por um dito que faz sorrir, um perfil que interessa, um par jovem cujo riso de amor causa inveja (RIO, p. 2 e 3, 2008).

O olhar de Baudelair pode ser compreendido como um primeiro passo para que os designers aumentem a percepção do que está a sua volta, como um exercício diário: aprender a ouvir e ver o que está ao redor (RIO, 2008). Sendo assim, ampliam-se os horizontes para compreensão das necessidades dos usuários, não se limitando ao senso comum. 


\section{0 designer no processo de imersão: olhar, ouvir e dar voz}

Ao analisar os procedimentos que orientam os processos de design, pode-se identificar como etapa inicial a definição de um problema que parte da identificação das necessidades para as quais o designer irá buscar uma solução. Como parte do processo metodológico, o designer cuidará da elaboração do briefing que consiste em um documento com o registro das necessidades, requisitos, informações relevantes sobre o contexto e definição do público-alvo (PAZMINO, 2009).

Nesse processo, o designer faz uso de métodos, conhecimentos e teorias de diversas disciplinas, fazendo-se necessário o uso de algumas técnicas de pesquisa, tais como: entrevista, observação, levantamento bibliográfico, dentre outros. Sobre o processo do design, Pazmino (2009) afirma:

(...) o processo de design não é apenas constituído pelas fases projetuais, mas pelas ações que se estabelecem entre elas. O conjunto dessas relações constitui a organização do processo. Se considerarmos que dentro do processo de projeto há uma sequência de passos que partem de uma necessidade ou um problema até a solução ou o produto, entendemos que existe em cada passo um conjunto de ações que são realizadas por indivíduos com pontos de vista cognitivamente diversos, havendo uma inter-relação de múltiplas ideias, informações, opiniões, teorias em intercâmbio contínuo.

Sendo assim, toda ação de design demanda o exercício contínuo de revisão, criação e reflexão sobre o uso de ferramentas que permitam ao designer a exteriorização do pensamento (PAZMINO, 2009). Pode-se dizer que todo processo de design promove o desenvolvimento de uma pesquisa aplicada. Esta permite a construção de um repertório para atuação, assim como a compreensão de procedimentos para inserção do design em um determinado contexto.

Diante disso, se faz necessário refletir sobre o processo de coleta de informações que irá orientar e fundamentar a ação de design. O próximo passo seria refletir sobre o modo como o designer fará a interpretação das informações coletadas e em sequência, pensar em como irá atuar. Sobre a coleta de informações, notam-se frequentes discussões acerca da participação dos usuários em pesquisas de caráter social. Assim, ações que envolvem a inserção do usuário no processo de design têm alcançado maior assertividade na configuração das soluções (PESSOA; BASTANI; MORAIS, 2015).

No que se refere à ação de design, esta é uma atividade que interfere diretamente no modo de vida das pessoas e, portanto, o discurso da ética é fundamental para se compreender a responsabilidade e papel do designer. Segundo Brandão (2005), as profissões que influenciam na segurança e na qualidade de vida das pessoas precisam considerar a ética da responsabilidade, que está na base da nova atitude de exigência social. Desse modo, o autor afirma:

O cidadão quer as garantias do profissionalismo, proteção contra o abuso e a ineficácia de poderes públicos e privados, as ameaças à sua segurança e identidade. Quer ter informação técnica e científica, opinião profissionalmente fundamentada quanto ao ambiente que afeta a sua vida (BRANDÃO, p. 59, 2005).

Assim, a ética surge como um caminho de discussão necessário ao longo de toda a ação de design. Isso envolve os procedimentos iniciais, orientados ao levantamento de informações até a execução de uma determinada solução. Diante disso, surgem alguns questionamentos sobre: como tornar os processos de design mais comprometidos com as reais necessidades das pessoas favorecendo a qualidade de vida? Ou mesmo: haveria algum modelo que permitisse ao designer obter maior compreensão acerca das necessidades dessas pessoas e do contexto da intervenção? Uma hipótese para tal questionamento seria oferecer condições para que essas pessoas sejam introduzidas no processo de design. 
Uma ação que vem de encontro a essa intenção é o design participativo. Segundo Santa Rosa e Moraes (2012), "a abordagem do design participativo além de promover a aproximação entre a equipe de desenvolvimento e usuários reduz erros de interpretação e falhas no entendimento pelos desenvolvedores". Nesse contexto, discute-se o design participativo como um exercício da responsabilidade do designer, que se faz por meio da descentralização do "poder" na tomada de decisões. Assim, o designer passa a atuar como um moderador do processo, permitindo um caminho possível para a ética na busca por procedimentos que favoreçam a qualidade de vida (PESSOA; BASTANI; MORAIS, 2015).

Nesse modelo, o designer atua de modo integrador, abdicando do poder centralizador de concentrar em suas mãos todo o processo de concepção da solução, passando a atuar de maneira compartilhada, na qual o "fazer e o criar" são resultados da ação dos agentes envolvidos numa determinada ação (PESSOA; BASTANI; MORAIS, 2015).

Diante das possibilidades de inserção dos usuários no processo de design, a coleta da percepção do usuário se apresenta como um aspecto relevante da ação. Assim, se faz necessário conhecer as preferências e o modo como cada pessoa significa e atribui sentidos. Abreu (2015) relata que recebemos milhares de estímulos do meio, os quais são filtrados de acordo com o nosso interesse, interpretados conforme conceitos, símbolos e mitos. Esses elementos se transformam em significados para o indivíduo ou para um grupo.

A partir dessa perspectiva, o designer em sua ação se torna o emissor, articula os atributos e materializa através de formas, cores, texturas, produzindo uma proposição que cria efeitos, capazes de dar sentido na mente do receptor ou intérprete, que é o usuário (ABREU, 2015). Abaixo a figura 01 demonstrará esse fluxo:

Figura 01: fluxo do processo de significação em design

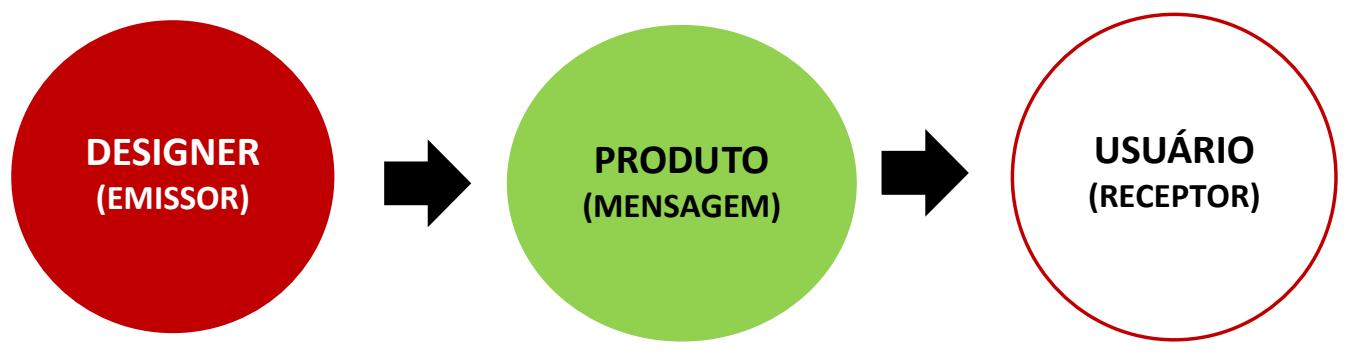

Fonte: Abreu (2015)

Desse modo, se o produto dessa mensagem não alcançar o receptor a ação de design não alcançará seu objetivo. Assim, pensar em novos modelos que permitam a inserção de usuários nesse processo permitirá a coleta da percepção e participação do usuário, receptor deste processo. Ampliamse assim, as atribuições de valor e sentido na ação de design. Buscar compreender como os produtos de design e os signos se constituem até a materialização dos conceitos são elementos a serem explorados na etapa de levantamento de informações, concernente ao briefing (ELLWANGER; NIEMEYER, 2003).

Propõem-se aqui, um caminho possível para o levantamento mais apurado de informações, por meio da adoção de procedimentos que permitam o levantamento das percepções dos usuários a partir de três atos: olhar, ouvir e dar voz, conforme podem ser observados na figura 02 : 
Figura 02: olhar, ouvir e dar voz.

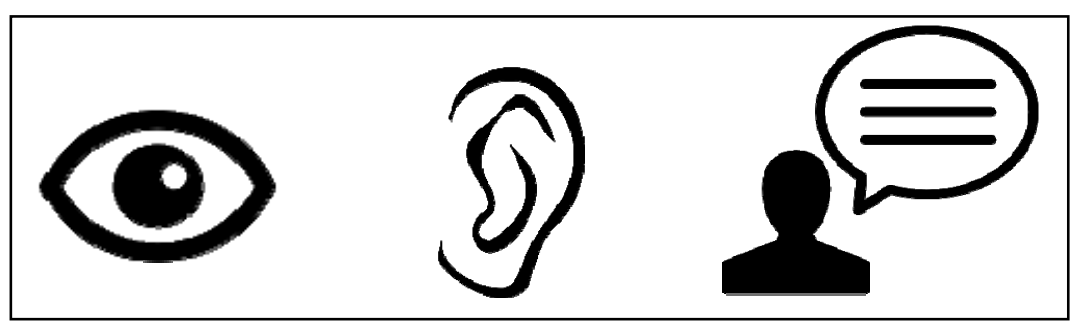

Fonte: Elaborado pelos autores.

O "olhar" diz respeito ao processo de imersão que permitirá ao designer se aprofundar na compreensão do contexto e se aproximar das realidades nas quais os usuários estão inseridos. Mais do que enxergar, o verbo "olhar" determina uma ação de penetrar além da superfície. Permite vivenciar e experimentar o contexto da ação. Nesse contexto, faz-se necessário adotar métodos e técnicas que possibilitem ao designer se inserir no campo da pesquisa e garantam a coleta de informações.

O "ouvir" se refere à dimensão da escuta, da capacidade de levantar informações a partir do saber e da experiência do outro, daquele que conhece com maior profundidade o contexto, devido a sua inserção naquela realidade em questão. $O$ uso de ferramentas de pesquisa, tais como: questionários, entrevistas, grupo focal podem ser mecanismos relevantes nesse processo.

$\mathrm{O}$ ato de "dar voz" permite a troca de saberes e o compartilhamento de informações que irão consolidar as ações a fim de democratizar o processo de tomada de decisão. Essa ação considera a participação de vários agentes, tais como: designer, usuários, especialistas, dentro de uma perspectiva interdisciplinar.

Nesse processo, os usuários devem ter influência nas decisões que os afetam, sendo natural que os usuários e designers tenham um olhar diferente na percepção do objeto de projeto. Por isso a união desses dois agentes no processo permitirá maior possibilidade de eficiência tanto na qualidade da solução quanto na aceitação da proposta. Assim, faz-se necessário criar condições no processo de design para que venham valorizar a inclusão e a democratização do compartilhamento dos saberes (BENKLER, 2006).

\section{Relato do projeto Praça de Bolso do Ciclista: ocupação criativa}

Como demonstração de uma ação que considerou o processo participativo, será apresentado relato acerca do projeto: "praça de bolso do ciclista", realizado na cidade de Curitiba / PR, em 2014. Formas criativas e participativas de se ocupar o espaço público vêm ganhando destaque por demonstrar como a união de recursos oriundos tanto da iniciativa pública, quanto de grupos e movimentos criados de maneira espontânea devido um fator em comum, podem contribuir para um novo pensamento diante do desafio da ressignificação, identidade e do senso de patrimônio coletivo na cidade.

Iniciativas que englobam um trabalho voluntário e participativo estão em voga. $\mathrm{O}$ caso recente é a 'Praça de Bolso do Ciclista', situada na região central de Curitiba. Como uma erva que desabrocha em lugar insalubre, a praça ocupa um espaço abandonado, caso tão corriqueiro nas grandes cidades, e redescobre a importância de se intervir na cidade para um bem coletivo. Abaixo segue figura 03 que ilustra o projeto elaborado para a praça: 
Figura 03: projeto do IPPUC para praça em homenagem à cultura da bicicleta

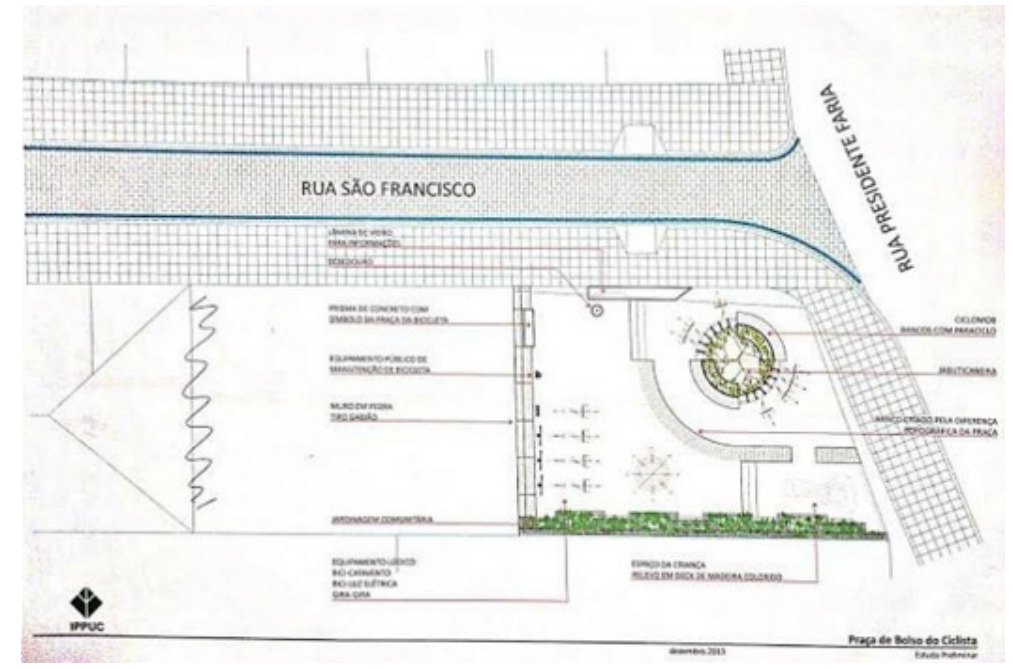

Fonte: http://migre.me/uiouS

Com uma área de 128 metros quadrados na esquina entre as ruas Presidente Faria e São Francisco, o Instituto de Pesquisa e Planejamento Urbano de Curitiba (IPPUC), projetou um local de convivência a partir da conjunção da dimensão simbólica, utilitária e comunitária do espaço. O terreno foi cedido pela prefeitura com o objetivo de propiciar o encontro de ciclistas em uma local que é emblemático para o movimento cicloativista da capital paranaense.

O projeto da praça foi apresentado pelas secretarias de obras e meio ambiente, juntamente com o IPPUC, aos ciclistas e à comunidade em uma reunião, onde a partir de propostas e sugestões dos usuários o projeto sofreu um redesenho para se adequar as demandas. A execução do projeto ficou a cargo da participação ativa da comunidade que colaborou por meio dos mutirões promovidos nos finais de semana. Para execução da obra a prefeitura cedeu o maquinário e repassou materiais para a construção, conforme figura 04 :

Figura 04: praça de bolso do ciclista

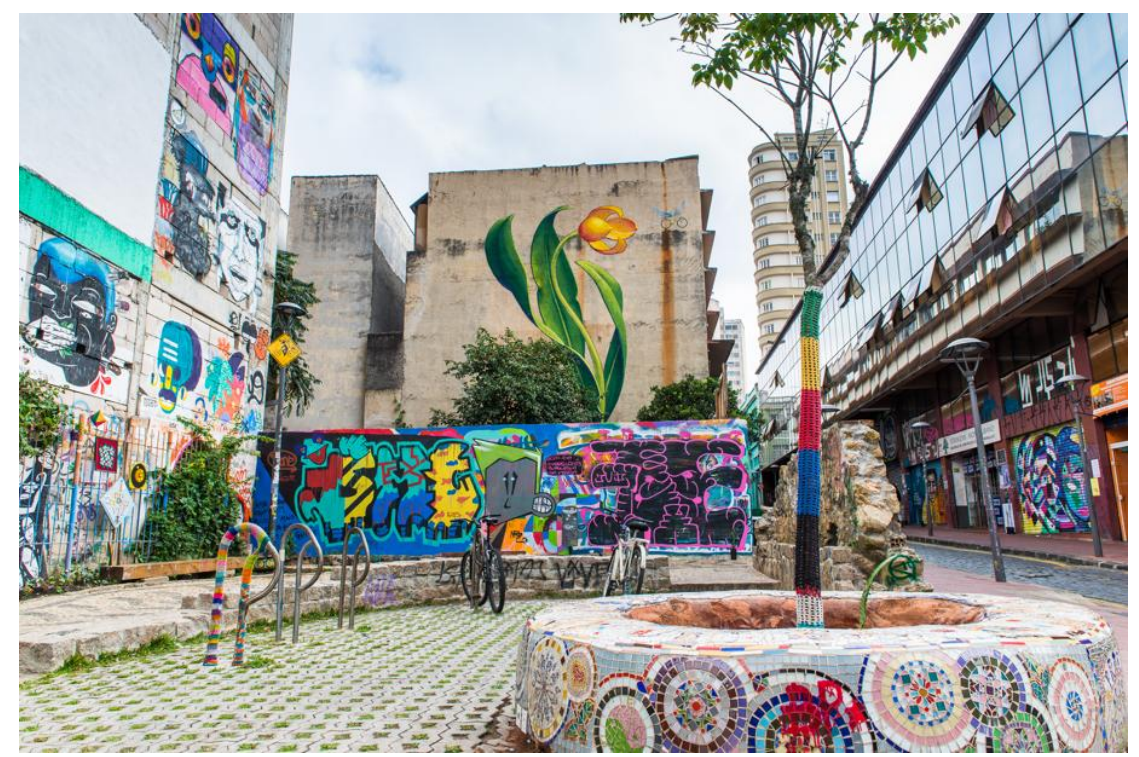

Fonte: http://migre.me/uk4Bt 


\section{Conclusão}

As atribuições 'comunitárias' do designer e esse novo olhar ao se projetar, não são uma novidade. O descobrimento de tais ferramentas e metodologias que incluem ativa e efetivamente o usuário no processo de projeto, ideação/criação/execução, não deveriam ser uma singularidade contemporânea. A natureza profissional do designer exige um posicionamento preocupado com as questões sociais que englobam o conceito de sustentabilidade tão difundido no meio acadêmico.

Os instrumentos participativos passam pelo senso de pertencimento e o empoderamento, transmitido à comunidade contemplada com propostas de empreendimentos sociais. Essa atenção voltada às etapas de projeto dá subsídio para uma identidade de território que se inicia no exercício de ouvir e olhar, se aproximar, daquele que irá usufruir do que será desenvolvido.

Essa empatia torna os resultados cada vez mais satisfatórios, pois desde o primeiro momento há o empenho de buscar soluções realmente úteis e necessárias a realidade trabalhada. Além de reforçar a coletividade por meio da inserção da comunidade no processo. Ao final, a possibilidade de dar voz é alcançada graças a um projeto fundamentado em ações participativas de design que levaram em consideração o usuário, seu território e sua linguagem expressa no espaço.

É importante trazer essa discussão para a sala de aula, para a formação de novos designers que defendam as temáticas sociais. A ética do design está na qualidade de vida e os artefatos humanos como parte do sistema. Deve-se assim, priorizar a introdução dessa mentalidade para atingir uma inovação social que exige medidas integradas de conhecimento. $\mathrm{O}$ design permite essa abordagem às emergências sociais para ativar uma mudança socialmente tangível, permitindo uma vida digna. Para atuar na sociedade contemporânea o profissional precisa assumir um papel mediador, sendo um facilitador para contribuir na promoção de um alto grau de participação social ativo.

\section{Design, identity and participatory methodologies}

\section{Abstract:}

The main challenge of the designer in the contemporaneity and development and development of solutions oriented to the questions of high complexity. The mediating character of design establishes quality processes, being a central factor for the humanization of technologies and cultural exchange. In this way, it is necessary to reflect on the development of new tools and working methods that foster dialogue and inclusion of social layers in the process of designing solutions that aim to meet the needs of this public. For this, the present article will present the city as a living context that integrates different people, habits and culture. In this sense, the designer has an important role to contribute to the valorization of the territorial identity, through participatory processes that can stimulate the sense of belonging. In this study, the objective is to reflect on the information gathering procedures that guide the design action with the intention of discussing new guidelines for collecting the perception and conducting actions that favor the insertion of the users. As procedures in this process, a dialectical flow supported by the concept "flaneur", presented by Charles Baudelaire, which includes a perceptive look at the context and which in this study consists of the ability to look, listen and give voice. As an object of study for this reflection, an account will be presented about the project: "pocket cyclist's square", held in the city of Curitiba / PR, in 2014. The action utilized participatory tools and they become reference for the design process, for its potential to convey the sense of belonging and empowerment to the community. It's believed that creative and participative ways of occupying public space can contribute to a new thinking in the face of the challenge of resignification, identity and the 
sense of collective patrimony in the city. In this new perspective, the designer becomes more than a designer, presents himself as an agent of connection and mediation between the identification of a problem and the search for a solution that considers broad perceptions of different agents inserted in the context of the action.

Keywords: Identity; territory; participatory design; giving voice.

\section{Referências}

ABREU, Simone Maria Brandão Marques de. Aspectos subjetivos relacionados ao design de ambientes: um desafio no processo projetual. Dissertação de mestrado - Programa de PósGraduação em Design da Universidade do Estado de Minas Gerais. Orientadora: Maria Regina Álvares Dias, 2015. $159 \mathrm{f}$.

BENKLER, Yochai. The wealth of networks: how social production transforms markets and freedom. USA: Yale University Press, 2006. 515p.

BORGES, A. Designer não é personal trainer e outros escritos. 2 ed. São Paulo: Edições Roari, 2003.

BOURDIEU, P. 1983. Gostos de classe e estilos de vida. In: Ortiz, R. (Org.); Fernandes, F. (Coord.). São Paulo: Ática, 1983.

BRANDÃO, Pedro. Ética e profissões, no design urbano convicção, responsabilidade e interdisciplinaridade: Traços da Identidade Profissional no Desenho da Cidade. Tese apresentada para a colação de título de doutor orientada pelo Dr. A. Remesar. Doutorado Espaço Público e Regeneração urbana: arte e sociedade. departamento de escultura universidade de Barcelona.

ELLWANGeR, Daniele; NIEMEYER, Lucy; PONTE, Raquel. Design Social e Ética em Peirce. In: Colóquio Internacional de Design, Edição 2013 - Design para os povos.

FERRARA, Lucrécia D’Aléssio. Leitura sem palavra. 5a ed. São Paulo: Ática, 2007.

FOUCAULT, Michel. Vigiar e Punir - História da violência nas prisões. 11ed. Ed. Vozes, Petrópolis, RJ. 1994.

KANT, Emmanuel. Versão eletrônica do livro: Crítica da razão pura. São Paulo: Abril Cultural, 1980 (Os pensadores). Disponível em: <http://migre.me/uhGSz>. Acesso no dia 05 de julho de 2016.

KRUCKEN, L. Competências para o design na sociedade contemporânea. Cadernos de Estudos Avançados em Design: Transversalidade / organização: Dijon De Moraes, Lia Krucken. - Barbacena: EdUEMG, 2008.

ONO, M. M. Design, cultura e identidade, no contexto da globalização. Revista Design em foco, julho-dezembro, vol I, nº 001. Salvador: Universidade do Estado da Bahia, 2004.

PESSOA, Sâmela S. M. V.; BASTANI, Kátia R. MORAIS, Mariana, A. Brincar e Criar: ambiente lúdico para uma brinquedoteca. In: Colóquio Internacional de Design, 2015.

SCHNEIDER, B. Design - uma introdução: O design no contexto social, cultural e econômico. São Paulo: Blücher, 2010. 